\title{
Large posterior perforation of duodenal ulcer: A rare surgical emergency
}

\author{
Faris Alaswad*
}

NMC Speciality Hospital, Dubai

Correspondence

Faris Alaswad, NMC Speciality Hospital, Dubai

Email: faris_alaswad@yahoo.com

History

- Received: 2019-04-20

- Accepted: 2019-05-14

- Published: 2019-06-07

DOI :

https://doi.org/10.15419/ajhs.v5i1.452

\section{Check for updates}

\section{Copyright}

(c) Biomedpress. This is an openaccess article distributed under the terms of the Creative Commons Attribution 4.0 International license.

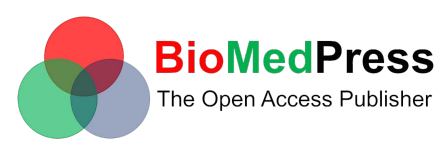

\begin{abstract}
A 20-year-old man was admitted with a complaint of a constant dull aching pain in the epigastrium and back for five days, with subsequent worsening and generalization of the pain. Clinically the abdomen was tender all over with board-like rigidity. Chest radiography revealed pneumoperitoneum, and a decision was made to explore the patient. During laparotomy, we found a peritoneal collection with no perforation in the anterior surface of the stomach, duodenum, or the entire gastrointestinal tract. After opening the lesser sac, we found a large perforation of the posterior wall of the duodenum. After direct repair with stitching through duodenotomy and duodenoplasty also done, the patient recovered and was discharged after 14 days. Posterior perforation of a duodenum ulcer is a very rare condition.
\end{abstract}

Key words: duodenal ulcer, posterior perforation, a surgical emergency

\section{INTRODUCTION}

Every year peptic ulcer affects three million people globally ${ }^{1}$. Complications are encountered in $10-20 \%$ of these patients, and $2-14 \%$ of the ulcers perforate ${ }^{2,3}$. A perforated peptic ulcer is relatively rare and usually occurs in the anterior aspect of the duodenum ${ }^{4}$. Posterior perforation of peptic ulcer is a different category of peptic ulcer perforation with a distinct clinical presentation ${ }^{5}$. Despite its rareness, awareness of this surgical emergency is essential, because it is usually associated with high morbidity and mortality, especially if the diagnosis is missed. Here we report a case of a large posterior perforation of a duodenal ulcer and a review of the literature.

\section{CASE REPORT}

A 20-year-old man was admitted with a complaint of a constant dull aching pain in the epigastrium for five days, which progressively worsened and generalized. No history of comorbidities, not smoker, no alcohol intake, insignificant family or medical history. The patient was febrile on admission, and his vital signs were unstable. The abdomen was tender all over with board-like rigidity. Chest radiography demonstrated pneumoperitoneum (ATTACHED XRAY), and the patient was diagnosed with generalized peritonitis due to perforated hollow viscus. An emergency laparotomy was therefore performed. During the laparotomy, collection of pus was found, with no perforation in the anterior surface of the stomach or duodenum; the rest of the gastrointestinal tract was regular.
The gastrocolic omentum was opened, and pus was drained out from the lesser sac. A 2-cm perforation of the posterior duodenal wall was noted. The lesser sac was approached through opening of the gastrohepatic omentum, pancreas was soaked with the gastric secretions and looked to be partially digested, the ulcer margins were attached to the pancreas, mobilization of the second part of the duodenum was done, the ulcers margins where biopsied, duodenotomy to approach and close the defect with stitching using 2-0 vicryl, Heineke-Mikulicz pyloroplasy at the end.

Recovery was not smooth, the patient was kept in an intensive care unit for ten days because of sepsis, respiratory distress syndrome, pancreatitis, at the end patient recovers entirely and was sent home after 20 days of hospitalization.

\section{DISCUSSION}

Posterior perforation of a duodenal ulcer is a rare condition. There are fewer than 30 cases reported in the literature. Wong and colleagues (2016) reviewed nine patients with posterior perforations, who were treated from January 1990 to June 2016. Their findings were sealed perforation, localized retroperitoneal abscess, and generalized peritoneal contamination of the lesser sac and peritoneal cavity ${ }^{5,6}$. In a series of 125 consecutive perforated peptic ulcer patients operated upon by Hamilton Bailey, there was only one case of perforation on the posterior surface of the duodenum $^{6}$. The great majority of benign duodenal ulcers 


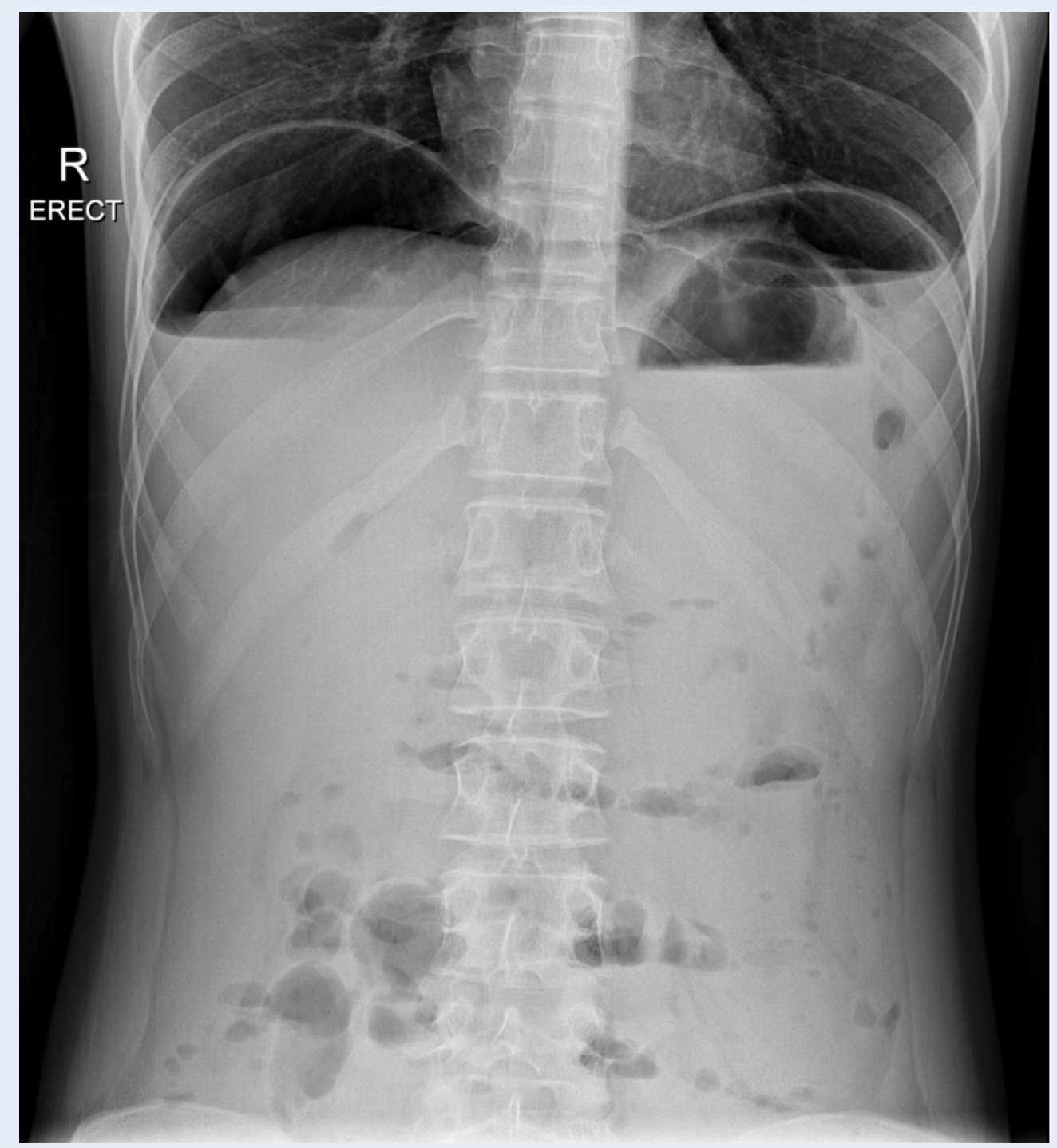

Figure 1: Chest radiography demonstrated pneumoperitoneum (ATTACHED XRAY), and the patient was diagnosed with generalized peritonitis due to perforated hollow viscus.

lie along the anterior aspect of the duodenum. However, $1-2 \%$ of ulcers lie in the posterior wall of the duodenum ${ }^{7}$. When posterior duodenal ulcer perforates, it usually penetrates the lesser sac behind the stomach. The lesser sac is a potential space and is less effective in sealing off the perforation; thus, the gastric content and pus will accumulate in the lesser sac, forming an abscess, and through the foramen of Winslow this fluid will pass into the peritoneal cavity, leading to generalized peritonitis ${ }^{5}$. That is why the clinical presentation of posterior duodenal perforation is less dramatic than that of the more common anterior perforations and is characterized by the late presentation. And because of the late presentation and missed diagnosis at laparotomy, posterior perforation is usually associated with high mortality ${ }^{1,2,5,8}$. These ulcers penetrate into the retroperitoneal space, which results in either retroperitoneal abscess formation, or the perforation will be sealed off by the local inflammatory reaction and fibrosis of the surrounding adherent retroperitoneal tissue ${ }^{5}$. Computed tomography (CT) scanning has an important role, particularly multidetector CT, in the diagnosis of perforated peptic ulcer and the determination of the site of perforation. There are particular findings in CT scanning that suggest duodenal posterior wall perforation, such as retrogastric air and/or fluid collection ${ }^{9,10}$. 


\section{CONCLUSION}

Posterior perforation of duodenal ulcers has high mortality. Delayed diagnosis due to insidious and presentation of symptoms and missed diagnosis at laparotomy are major contributory factors. Posterior perforations if delayed, are associated with peritonitis sepsis and multi-organ failure. In cases of purulent peritonitis performing the definitive surgical procedure is a contraindication, and only damage controlled surgery should be performed. In the badly scarred and contracted duodenum the matter of both secure closure and adequate channel for gastric emptying must be considered. The operating surgeon responsible for the care of the individual case is free to select a form of therapy that varies from the standard protocol if he/she considers such a selection to be in the best interest of the patient.

\section{COMPETING INTERESTS}

The author(s) declare that they have no competing interests.

\section{REFERENCES}

1. Jarrett F, Donaldson GA. The ulcer diathesis in perforated duodenal ulcer disease. Experience with 252 patients during a twenty-five year period. Am J Surg. 1972;123(4):406-10. 5013760. Available from: 10.1016/0002-9610(72)90191-2.
2. Jordan GL, DeBakey ME, Duncan JM. Surgical management of perforated peptic ulcer. Ann Surg. 1974;179(5):62833. 4823840. Available from: 10.1097/00000658-19740500000015.

3. Jordan PH, Hendenstedt S, Korompai FL, Lundquist G. Vagotomy of the fundic gland area of the stomach without drainage. A definitive treatment for perforated duodenal ulcer. Am J Surg. 1976;131(5):523-6. 1275136. Available from: 10.1016/0002-9610(76)90002-7.

4. Jordan PH, Korompai FL. Evolvement of a new treatment for perforated duodenal ulcer. Surg Gynecol Obstet. 1976;142(3):391-5. 1251322.

5. Paster SB, Brogdon BG. Roentgenographic diagnosis of pneumoperitoneum. JAMA. 1976;235(12):1264-7. 946240. Available from: 10.1001/jama.1976.03260380058035.

6. Pierandozzi JS, Hinshaw DB, Stafford CE. Vagotomy and pyloroplasty for acute perforated duodenal ulcer. A report of seventy-five cases. Am J Surg. 1960;100(2):245-50. 14432807. Available from: 10.1016/0002-9610(60)90297-X.

7. Sawyers JL, Herrington JL. Perforated duodenal ulcer managed by proximal gastric vagotomy and suture plication. Ann Surg. 1977;185(6):656-60. 324418. Available from: 10.1097/ 00000658-197706000-00007.

8. Seeley SF, Campbell D. Nonoperative treatment of perforated peptic ulcer; a further report. Surg Gynecol Obstet. 1956;102(5):435-46. 13311756.

9. Sisel RJ, Donovan AJ, Yellin AE. Experimental fecal peritonitis. Influence of barium sulfate or water-soluble radiographic contrast material on survival. Arch Surg. 1972;104(6):7658. 5029407. Available from: 10.1001/archsurg.1972. 04180060015003.

10. Taylor H. Guest lecture: the nonsurgical treatment of perforated peptic ulcer. Gastroenterology. 1957;33(3):353-68 13474170. Available from: 10.1016/S0016-5085(19)35727-0. 